\title{
Ordinal logistic regression model describing factors associated with extent of nodal involvement in oral cancer patients and its prospective validation
}

\author{
Vishwajeet Singh ${ }^{1}$, Sada Nand Dwivedi ${ }^{1 *}$ (1) and S. V. S. Deo ${ }^{2}$
}

\begin{abstract}
Background: Oral cancer is the most common cancer among Indian men, and has strong tendency of metastatic spread to neck lymph node which strongly influences prognosis especially 5 year survival-rate and also guides the related managements more effectively. Therefore, a reliable and accurate means of preoperative evaluation of extent of nodal involvement becomes crucial. However, earlier researchers have preferred to address mainly its dichotomous form (involved/not-involved) instead of ordinal form while dealing with epidemiology of nodal involvement. As a matter of fact, consideration of ordinal form appropriately may increase not only the efficiency of the developed model but also accuracy in the results and related implications. Hence, to develop a model describing factors associated with ordinal form of nodal involvement was major focus of this study.

Methods: The data for model building were taken from the Department of Surgical Oncology, Dr.BRA-IRCH, AllMS, New Delhi, India. All the OSCC patients (duly operated including neck dissection) and confirmed histopathologically from 1995 to 2013 were included. Further, another data of 204 patients collected prospectively from 2014 to 2015 was considered for the validation of the developed model. To assess the factors associated with extent of nodal involvement, as a first attempt in the field of OSCC, stepwise multivariable regression procedure was used and results are presented as odds-ratio and corresponding 95\% confidence interval (Cl). For appropriate accounting of ordinal form, the ordinal models were assessed and compared. Also, performance of the developed model was validated on a prospectively collected another data.
\end{abstract}

Results: Under multivariable proportional odds model, pain at the time of presentation, sub mucous fibrosis, palpable neck node, oral site and degree of differentiation were found to be significantly associated factors with extent of nodal involvement. In addition, tumor size also emerged to be significant under partial-proportional odds model.

(Continued on next page)

\footnotetext{
* Correspondence: dwivedi7@hotmail.com; dwivedi7@hotmail.com;

dwivedi@aiims.ac.in

${ }^{1}$ Department of Biostatistics, All India Institute of Medical Sciences, New

Delhi 110029, India

Full list of author information is available at the end of the article
}

(c) The Author(s). 2020 Open Access This article is licensed under a Creative Commons Attribution 4.0 International License, which permits use, sharing, adaptation, distribution and reproduction in any medium or format, as long as you give appropriate credit to the original author(s) and the source, provide a link to the Creative Commons licence, and indicate if changes were made. The images or other third party material in this article are included in the article's Creative Commons licence, unless indicated otherwise in a credit line to the material. If material is not included in the article's Creative Commons licence and your intended use is not permitted by statutory regulation or exceeds the permitted use, you will need to obtain permission directly from the copyright holder. To view a copy of this licence, visit http://creativecommons.org/licenses/by/4.0/ The Creative Commons Public Domain Dedication waiver (http://creativecommons.org/publicdomain/zero/1.0/) applies to the data made available in this article, unless otherwise stated in a credit line to the data. 
(Continued from previous page)

Conclusions: The analytical results under the present study reveal that in case of ordinal form of the outcome, appropriate ordinal regression may be a preferred choice. Present data suggest that, pain, sub mucous fibrosis, palpable neck node, oral site, degree of differentiation and tumor size are the most probable associated factors with extent of nodal involvement.

Keywords: Ordinal logistic regression, Oral cancer, Nodal involvement, Squamous cell carcinoma

\section{Background}

In India, in terms of prevalence and incidence, oral cancer ranks first among men and overall at rank three, however regarding related mortality it is at third position in men (GLOBOCAN 2012) [1]. The prognosis of oral cancer including 5 year survival rate may get highly affected due to its metastatic spread to neck lymph node [2]. As a result, the regional control and overall survival may also get affected [3-7]. In other words, the outcome of oral cancer may significantly change due to the nodal involvement. Hence, appropriate management of the cervical lymph nodes is an important part of oral cancer therapy [8-13]. However, there has been controversy over the indication, timing and methods of neck dissection $[12,13]$. Difficulties in early diagnosing thus restrict the treatment carried out by surgeons [14]. A reliable and accurate means of preoperative evaluation of cervical lymph node metastasis is therefore crucial for the correct management of oral cancer $[8,10,13,15,16]$. Also, understanding of its associated factors may provide clues to the clinicians for better management.

There are negligible numbers of studies dealing with analysis of nodal involvement among oral cancer patients. Most of them have focused either on occult nodal metastasis only or a specific oral site i.e., tongue, lip or buccal mucosa or stages [2, 17-27]. Further, they have dealt with only presence/absence of nodal involvement, not in the ordinal form. It is well known that, ignoring the ordering has its own disadvantage mainly because it does not fully utilize the available information [28]. For example, Armstrong and Sloan [29] have reported that compared to a cumulative logit model for a five level ordered response, use of logistic model resulted into a loss of $25-50 \%$ of efficiency. To the best of our knowledge, this is the first such study dealing with the ordinal form of extent of involved nodes among oral cancer patients.

Keeping in view of the above points, objective of this study was to develop an ordinal logistic regression model to find out the factors associated with ordinal form of involved nodes and validate it on temporal data.

\section{Methods}

Data

The utilized dataset under the present study is same as that considered while assessing the factors associated with nodal involvement (yes/no) among oral squamous cell carcinoma patients $[30,31]$. As such, the data maintained at Department of Surgical Oncology, Institute Rotary Cancer Hospital (IRCH), AIIMS, New Delhi, India for patients with histopathologically proven oral squamous cell carcinoma who went under surgery including neck dissection was considered. Out of data of 1123 oral cancer patients available during 1995 to 2013, 945 fulfilled the inclusion criteria. Further, prospectively collected data of 204 patients from January 2014 to December 2015 was used for the temporal validation of the developed ordinal model. The number of involved nodes of each patient was collected from their histopathological reports. In view to utilize maximum available information for more accurate results, ordinal categories mainly relied on desired varying management strategies being adopted by the oncologists according to cut-off values of involved nodes. Accordingly it was considered as $0,1,2-4$ and $>4$ involved nodes in ordinal categories. The covariates in this study remain same as those under dichotomous model $[30,31]$. Statistical software, STATA/SE version 14.2 (StataCorp LP, College Station, TX, USA), was used for the analysis.

\section{Statistical analysis}

Categorical variables were described using absolute/relative frequency distribution and quantitative variables using measures of central tendency/location like mean (standard deviation)/median (quartile range). The association between qualitative independent variables, was assessed using Chi-square test/ Fisher's exact test. To assess association between two quantitative variables, Pearson/Spearman's correlation coefficient was used. Collinearity between the covariates was assessed by Cramer's $\mathrm{V}$ as 0.7 and more. To find out the factors associated with ordinal form of nodal involvement, stepwise ordinal logistic regression procedure was used. Variables which were found to be significant at the level of $25 \%$ under crude association analysis (univariable analysis) and/or on the basis of their clinical relevance were taken as a sub-set of covariates for stepwise regression. Results are presented in the form of odds ratio and corresponding 95\% confidence interval (CI). Brant test was used for proportionality assumption [32]. The model performance was assessed using measure of discrimination and 
calibration (i.e. the accuracy of the prediction probability of nodal involvement). Discrimination performance was evaluated using Average Dichotomous C-index, Generalized C-index and Set wise C-index (ORC) [33]. Calibration of the predicted probabilities under the developed model was investigated using M.W. Fagerland and D.W. Hosmer test for goodness of fit [34] and specification error by linktest [35]. The equal spaced integer weight score was used to discriminate the individuals regarding calibration and discrimination ability of the developed model [36].

\section{Statistical models}

There are different ordinal logistic regression models to tack care of ordinal form of outcomes. These different ordinal regression models have different ways to form their logits. For example, proportional odds model (considered as cumulative higher category(s) verses cumulative remaining lower category(s)); continuation ratio model (considered as cumulative higher category(s) verses just lower category alone); and adjacent category model (between any of two consecutive categories). Accordingly every form of the logit has its own benefits or limitation, one can use the models as per specific need. To be more specific, continuation ratio model and adjacent category model do not relay on complete data set. In epidemiological and biomedical applications, proportional odd model (POM) is often used. However, sometime continuation ratio model is also used [37, 38]. Further, choice between the POM and CRM models relies on the goals of the statistical analysis. As obvious, in case of nodal involvement, interpretation under POM will remain more logical and meaningful. However, if the proportionality assumption does not fulfill, partial proportional odds model may be a better choice [35, 39]. Further, choice between proportional odds and partial proportional odds models was assessed using likelihood ratio test, LR, AIC and BIC.

\section{Proportional odds model (POM)}

If $\log$ odds ratio across the cut points is identical, i.e. proportional odds assumption is satisfied, the proportional odds model is used. The proportional odds model was initially proposed by Walker and Duncan [40] as cumulative logit model, but later it was named as proportional odds model by McCullagh [37]. In case of the present study, independent observations on 945 patients were available. As described earlier, observation on the nodal involvement $(\mathrm{Y})$ for each patient is classified into either of four categories. Likewise, covariates $\left(x_{i}\right)$ denote the $\mathrm{p}$-dimensional vector of covariates $(\mathrm{i}=1,2 \ldots \mathrm{p})$, containing the observation on the full set of $\mathrm{p}$ explanatory variables. Accordingly, the dependency of $\mathrm{Y}$ on $x_{i}$ may be expressed as:

$$
\operatorname{Pr}\left(Y \geq y_{j} \mid x_{i}\right)=\frac{1}{1+\exp \left(-\alpha_{j}-x_{i}^{\prime} \beta\right)}, j=1,2,3
$$

Or

$$
\log \left[\frac{\operatorname{Pr}\left(Y \geq y_{j} \mid x\right)}{1-\operatorname{Pr}\left(Y \geq y_{j} \mid x\right)}\right]=\alpha_{j}+x_{i}^{\prime} \beta, j=1,2,3
$$

Where, $\operatorname{Pr}\left(Y \geq y_{j}\right)$ is the cumulative probability of the event $\left(Y \geq y_{j}\right) ; \alpha_{j}$ are the respective intercept parameters; $\beta$ is a (p by 1 ) vector of regression coefficients corresponding to $x_{i}$ covariates.

\section{Partial proportional odds model (PPOM)}

If identical log odds ratio assumption under POM is not fulfilled for some of the covariates, partial proportional odds model may be used [41]. Out of the two approaches available in this regard, unconstrained partial proportional odds model and constrained partial proportional odds model, unconstrained PPOM model was used due to unavailability of prior knowledge or beliefs regarding constraints and also availability of computational facility [42]. The PPOM permits non proportional odds for a subset of $\mathrm{q}$ of the p-predictors $(\mathrm{q} \leq \mathrm{p})$. The unconstrained PPOM cumulative probability may be defined as:

$$
\operatorname{Pr}\left(Y \geq y_{j} \mid x_{i}\right)=\frac{1}{1+\exp \left(-\alpha_{j}-x_{i}^{\prime} \beta-t^{\prime} \gamma_{j}\right)}, j=1,2,3
$$

Where $x_{i}$ is a ( $\mathrm{p}$ by 1 ) vector containing the values of observation $i$ on the full set of $\mathrm{p}$ explanatory variables, $\beta$ is a (p by 1 ) vector of regression coefficients associated with $\mathrm{p}$ variables. Further, $t$ is a (1 by q) vector of $\mathrm{q}-$ covariates, containing the values of observation $i$ on that subset of the $\mathrm{p}$ explanatory variables for which proportionality assumption is either not fulfilled or is to be tested; and $\gamma_{j}$ is a (q by 1 ) vector of regression coefficients associated with the q covariates. Accordingly, $t^{\prime} \gamma_{j}$ is the increment associated with jth cumulative logit $(1<=\mathbf{j}<=3)$, where $\gamma_{1}$ is equal to 0 . If $\gamma_{j}=0$ for all $\mathbf{j}$, then this model reduces to proportional odds model. Accordingly, the proportional odds assumption for the q variables in $\mathrm{t}$ is a test of the null hypothesis that $\gamma_{j}=0$ for all $\mathrm{j}=2,3$.

\section{Results}

The ordinal logistic regression model was developed using data on 945 patients, where as the data of another 204 patients was used for temporal validation of the developed model. Out of 945 patients, females were 212 
(22.4\%). Majority of the patients were in the age group 40 to 60 years $549(58.1 \%)$ and in lower/lower middle socio-economic class 751 (79.5\%). The distribution of number of involved nodes were as; no node involved: 569 (60.21\%); 1 node involved: 149 (15.77\%); 2-4 nodes involved: 162 (17.14\%) and $>4$ nodes involved: 65 (6.88\%).

Out of 39 available variables, a set of 19 covariates were considered for stepwise regression procedure, among which 9 variables were selected on the basis of its crude association at 25\% level of significance and 10 variables on its clinical relevance. Collinearity and first order effect modifier were assessed before developing the multivariable model. They were absent in the present dataset. The distribution of nodal involvement and its associations with covariates are presented in Table 1.

Under multivariable regression analysis, proportional odds assumption was found to be satisfactory for each of the considered covariates selected for developing final model except histopathological tumor size. Moreover, overall proportionality assumption was not violated $(p=$ 0.97). Accordingly, both the models (POM and PPOM) were developed and compared.

Interestingly, the results under proportional odds multivariable regression analysis emerged to be similar to those reported under binary form of nodal involvement [30]. To be more specific, pain at presentation, SMF, palpable neck node, oral site and degree of differentiation were retained to be significantly associated factors also with higher extent of nodal involvement. The patients presenting with pain were $37 \%$ more likely to have higher order of nodal positivity as compared to lower [1.37 (1.05 to 1.78)], whereas SMF was protective and patients with SMF had 57\% less chance for higher frequency of node involvement [0.43 (0.21 to 0.90)]. Patients other than well differentiated tumors were more likely for presence of positive node [1.41 (1.07 to 1.86)] (Table 2).

Like proportional odds model, under multivariable partial proportional odds model, pain at the time of presentation, SMF, palpable neck node, oral site and degree of differentiation were found to be significantly associated factors. In addition, tumor size also emerged to be significant. For patients with large tumor size, the chance of involving higher number of positive nodes went up. The patients with tumor size more than $4 \mathrm{~cm}$ had more than two fold chance to be involved with more than 4 numbers of positive nodes. The detailed results under multivariable regression analysis are presented in (Table 3).

The comparative appraisal of both the models (Table 2, Table 3) revealed that partial proportional odds model stands to be preferred as indicated by LR and AIC (Table 4). Likelihood-ratio test also suggests the same $(p=0.004)$.

\section{Assessment of the model}

Fagerland and Hosmer test [34] for goodness of fit suggests $(p=0.88)$ that our developed model describes the distribution of nodal involvement satisfactorily. Further, link test suggest $(p=0.65)$ that there was no specification error in the developed partial proportional odds model. For discrimination ability of the developed model, Average Dichotomous C-index, Generalized Cindex and Set wise C-index (ORC) were used [33]. The Average Dichotomous C-index values of the developed model was found to be 0.67 , which suggests that probability to correctly discriminate a case with a lower outcome level from a case with higher outcome level was 0.67 . However, Generalized C-index value was observed as 0.635 , which means that probability to discriminate two cases from different categories was 0.635. Further, set wise $\mathrm{C}$-index (ORC) value of the model was 0.634 . It implies that the probability of correct discrimination in a pair of cases from two randomly chosen categories was 0.634 .

\section{Validation of the developed model}

As described earlier, temporal validation [43] of the developed model was evaluated on another dataset of 204 patients (validation data), collected prospectively from the same centre. The goodness of fit test on validation data also suggests $(p=0.35)$ that the developed model sustains its ability to describe the distribution of nodal involvement satisfactorily. In this case, the probability values of all the three indices (i.e. Average Dichotomous C-index, Generalized C-index and Set wise C-index (ORC)) providing discrimination ability of the ordinal logistic regression were $0.66,0.63$ and 0.64 respectively, which again indicates that the developed model performs equally on validation data. The analytical results amply reveal that the developed model remains to be generalizable and acceptable.

\section{Discussion}

In biomedical research, in addition to frequent emergence of ordinal categorical data, sometime ordinal categories are the result of grouping of quantitative data [44]. However, as known in case of change in origin and scale, dichotomization or ignoring the order has its own disadvantage. Armstrong and Sloan (1989) found that compared to a cumulative logit model of a five level ordered response, logistic model attains only $50-75 \%$ of efficiency [29].

In this study, ordinal categories mainly relied on desired varying management strategies being adopted by the oncologists according to cut-off values. Accordingly, number of involved cervical nodes were categorized as 0 , $1,2-4$ and $>4$ involved nodes. Until now, there is no study considering the ordinal form of nodal involvement 
Table 1 Distribution and association of nodal involvement with various covariates

\begin{tabular}{|c|c|c|c|c|c|c|c|}
\hline Variables & & Freq (\%) & No Nodes & 1 Node $(+)$ & 2-4 Node(+) & $>4$ Node $(+)$ & $P$ value \\
\hline \multirow[t]{2}{*}{ Gender } & Female & $212(22.4)$ & $116(54.7)$ & 31 (14.6) & $44(20.8)$ & $21(9.9)$ & \\
\hline & Male & 733 (77.6) & $453(61.8)$ & $118(16.1)$ & $118(16.1)$ & $44(6.0)$ & 0.062 \\
\hline Age & $<40$ & $184(19.5)$ & $113(61.4)$ & 31 (16.8) & $29(15.8)$ & $11(6.0)$ & \\
\hline \multirow[t]{2}{*}{ (years) } & $40-60$ & $549(58.1)$ & $322(58.6)$ & $90(16.4)$ & $94(17.1)$ & $43(7.8)$ & \\
\hline & $>60$ & $212(22.4)$ & $134(63.2)$ & $28(13.2)$ & 39 (18.4) & $11(5.2)$ & 0.682 \\
\hline Soc-Eco & LC & $252(26.7)$ & $151(59.9)$ & $37(14.7)$ & 45 (17.9) & $19(7.5)$ & \\
\hline \multirow[t]{3}{*}{ Status } & LMC & 499 (52.8) & 309 (61.9) & $70(14.0)$ & $84(16.8)$ & $36(7.2)$ & \\
\hline & UMC & $174(18.4)$ & $97(55.7)$ & 38 (21.8) & 31 (17.8) & $8(4.6)$ & \\
\hline & UC & $20(2.1)$ & $12(60.0)$ & $4(20.0)$ & $2(10.0)$ & $2(10.0)$ & 0.451 \\
\hline \multirow[t]{2}{*}{ Pain } & No & $521(55.1)$ & $330(63.3)$ & 80 (15.4) & 84 (16.1) & $27(5.2)$ & \\
\hline & Yes & $424(44.9)$ & $239(56.4)$ & 69 (16.3) & 78 (18.4) & $38(9.0)$ & 0.056 \\
\hline Dur. Of & $<3$ & $250(26.5)$ & $146(58.4)$ & $43(17.2)$ & 41 (16.4) & $20(8.0)$ & \\
\hline Symp. & $>=3 \&<6$ & $372(39.4)$ & $216(58.1)$ & $60(16.1)$ & $66(17.7)$ & $30(8.1)$ & \\
\hline (months) & $>=6$ & $323(34.1)$ & 207 (64.1) & $46(14.2)$ & $55(17.0)$ & $15(4.6)$ & 0.448 \\
\hline \multirow[t]{2}{*}{ Leukoplakia } & No & $862(91.2)$ & $513(59.5)$ & $140(16.2)$ & 151 (17.5) & $58(6.7)$ & \\
\hline & Yes & $83(8.8)$ & $56(67.5)$ & $9(10.8)$ & $11(13.3)$ & $7(8.4)$ & 0.345 \\
\hline \multirow[t]{2}{*}{ Smoking } & No & $592(62.6)$ & $342(57.8)$ & 97 (16.4) & $106(17.9)$ & $47(7.9)$ & \\
\hline & Yes & $353(37.4)$ & $227(64.3)$ & $52(14.7)$ & $56(15.9)$ & $18(5.1)$ & 0.166 \\
\hline \multirow[t]{2}{*}{ SMF } & No & 904 (95.7) & $538(59.5)$ & $142(15.7)$ & $160(17.7)$ & $64(7.1)$ & \\
\hline & Yes & $41(4.3)$ & 31 (75.6) & $7(17.1)$ & $2(4.9)$ & $1(2.4)$ & 0.081 \\
\hline Dur. Risk & 0 & $162(17.2)$ & $93(57.4)$ & $24(14.8)$ & $27(16.7)$ & 18 (11.1) & \\
\hline \multirow[t]{4}{*}{ (months) } & $\leq 60$ & $92(9.7)$ & $52(56.5)$ & $11(12.0)$ & $23(25.0)$ & $6(6.5)$ & \\
\hline & $>60 \& \leq 120$ & $240(25.4)$ & $136(56.7)$ & $49(20.4)$ & $40(16.7)$ & $15(6.3)$ & \\
\hline & $>120 \& \leq 240$ & $262(27.7)$ & $167(63.7)$ & $42(16.0)$ & $41(15.7)$ & $12(4.6)$ & \\
\hline & $>240$ & $189(20.0)$ & $121(64.0)$ & $23(12.2)$ & $31(16.4)$ & $14(7.4)$ & 0.117 \\
\hline cTumor & UIG & $386(40.8)$ & 221 (57.2) & 69 (17.9) & $70(18.1)$ & $26(6.7)$ & \\
\hline \multirow[t]{2}{*}{ Growth } & UPG & $539(57.0)$ & $335(62.1)$ & $78(14.5)$ & 89 (16.5) & $37(6.9)$ & \\
\hline & Other & $20(2.2)$ & $13(65.0)$ & $2(10.0)$ & $3(15.0)$ & $2(10.0)$ & 0.710 \\
\hline \multirow[t]{4}{*}{ c T Stage } & $\mathrm{T} 1$ & $80(8.5)$ & $51(63.7)$ & $13(16.3)$ & $9(11.2)$ & $7(8.8)$ & \\
\hline & $\mathrm{T} 2$ & $252(26.7)$ & $145(57.5)$ & $52(20.6)$ & $46(18.3)$ & $9(3.6)$ & \\
\hline & T3 & 99 (10.5) & $61(61.6)$ & $11(11.1)$ & $17(17.2)$ & $10(10.1)$ & \\
\hline & T4 & $514(54.3)$ & $312(60.7)$ & $73(14.2)$ & $90(17.5)$ & $39(7.6)$ & 0.102 \\
\hline \multirow[t]{2}{*}{ Trismus } & No & 724 (76.6) & $437(60.4)$ & $107(14.8)$ & $126(17.4)$ & $54(7.5)$ & \\
\hline & Yes & $221(23.4)$ & $132(59.7)$ & $42(19.0)$ & $36(16.3)$ & $11(5.0)$ & 0.312 \\
\hline \multirow[t]{2}{*}{ cSkinlnv } & No & $721(76.3)$ & $429(59.5)$ & $121(16.8)$ & $125(17.3)$ & $46(6.4)$ & \\
\hline & Yes & $224(23.7)$ & $140(62.5)$ & $28(12.5)$ & 37 (16.5) & $19(8.5)$ & 0.333 \\
\hline \multirow[t]{2}{*}{ OCF } & No & 916 (96.9) & $549(59.9)$ & $145(15.8)$ & $159(17.4)$ & $63(6.9)$ & \\
\hline & Yes & $29(3.1)$ & $20(69.0)$ & $4(13.8)$ & $3(10.3)$ & $2(6.9)$ & 0.738 \\
\hline \multirow[t]{2}{*}{ cBonelnv } & No & $694(73.4)$ & $426(61.4)$ & $112(16.1)$ & $111(16.0)$ & $45(6.5)$ & \\
\hline & Yes & 251 (26.6) & $143(57.0)$ & $37(14.7)$ & $51(20.3)$ & $20(8.0)$ & 0.331 \\
\hline \multirow[t]{2}{*}{ cNeck Node } & No & $233(24.7)$ & $171(73.4)$ & $33(14.2)$ & $23(9.9)$ & $6(2.6)$ & \\
\hline & Yes & $712(75.3)$ & 398 (55.9) & $116(16.3)$ & $139(19.5)$ & $59(8.3)$ & $<0.001$ \\
\hline \multirow[t]{2}{*}{ Oral Site } & BM & $272(28.7)$ & $175(64.3)$ & $42(15.4)$ & $41(15.1)$ & $14(5.2)$ & \\
\hline & Tongue & $200(21.3)$ & $110(55.0)$ & $33(16.5)$ & 38 (19.0) & $19(9.5)$ & \\
\hline
\end{tabular}


Table 1 Distribution and association of nodal involvement with various covariates (Continued)

\begin{tabular}{|c|c|c|c|c|c|c|c|}
\hline Variables & & Freq (\%) & No Nodes & 1 Node (+) & 2-4 Node(+) & $>4$ Node $(+)$ & $P$ value \\
\hline & Alvelobuccal & 177 (18.7) & $100(56.5)$ & $30(17.0)$ & 31 (17.5) & $16(9.0)$ & \\
\hline & Alveolus & $104(11.0)$ & $59(56.7)$ & $20(19.2)$ & $18(17.3)$ & $7(6.7)$ & \\
\hline & $C A \& F O M$ & $90(9.5)$ & $62(68.9)$ & $9(10.0)$ & $14(15.6)$ & $5(5.6)$ & \\
\hline & RMT & $54(5.7)$ & 37 (68.5) & $7(13.0)$ & $8(14.8)$ & $2(3.7)$ & \\
\hline & Lip & $48(5.1)$ & $26(54.2)$ & $8(16.7)$ & $12(25.0)$ & $2(4.2)$ & 0.551 \\
\hline \multirow[t]{2}{*}{ Deg. of Diff. } & WD & $658(69.6)$ & $410(62.3)$ & $102(15.5)$ & $104(15.8)$ & $42(6.4)$ & \\
\hline & Others & $287(30.4)$ & $159(55.4)$ & $47(16.4)$ & $58(20.2)$ & $23(8.0)$ & 0.194 \\
\hline Tumor Size & $<=2$ & $256(27.1)$ & $165(64.4)$ & 39 (15.2) & $41(16.0)$ & $11(4.3)$ & \\
\hline \multirow[t]{2}{*}{ (cm) } & $>2$ and $<=4$ & $466(49.3)$ & $270(57.9)$ & 86 (18.5) & $80(17.2)$ & $30(6.4)$ & \\
\hline & $>4$ & $223(23.6)$ & $134(60.1)$ & $24(10.8)$ & $41(18.4)$ & $24(10.8)$ & 0.022 \\
\hline Total & & $945(100)$ & $569(60.2)$ & 149 (15.8) & $162(17.1)$ & $65(6.9)$ & \\
\hline
\end{tabular}

LC Lower class, LMC Lower middle class, UC Upper class, UMC Upper middle class, UIG Ulceroinfiltrative, UPG, ulceroproliferative, WD Well Differentiated; Deg. of Diff. Degree of differentiation, cSkin Inv clinical skin involvement, cBone Inv clinical bone involvement, SMF sub mucous fibrosis.

while assessing its associated factors. The available studies have dealt with only binary form of nodal involvement [2, 14, 24, 30, 45-47].

In the present study, POM seems to be appropriate as overall model did not violate the proportional odds assumption significantly. However, one of the covariates was found to violate this assumption. Theoretical ground or empirical tests do not provide clear guidelines about

Table 2 Factors associated with cervical lymph node involvement using proportional odds model

\begin{tabular}{|c|c|c|c|}
\hline Variables & & UOR(95\%Cl) & $\mathrm{AOR}(95 \% \mathrm{Cl})^{*}$ \\
\hline \multirow[t]{2}{*}{ Pain } & No & 1 & 1 \\
\hline & Yes & 1.37 (1.07 to 1.77$)$ & $1.37(1.05$ to 1.78$)$ \\
\hline \multirow[t]{2}{*}{ SMF } & No & 1 & 1 \\
\hline & Yes & 0.44 (0.22 to 0.90$)$ & 0.43 (0.21 to 0.90$)$ \\
\hline \multirow[t]{2}{*}{ cNeck Node } & No & 1 & 1 \\
\hline & Yes & 2.28 (1.66 to 3.14$)$ & 2.42 (1.73 to 3.39$)$ \\
\hline \multirow[t]{7}{*}{ Oral Site } & $\mathrm{BM}$ & 1 & 1 \\
\hline & Tongue & 1.53 (1.07 to 2.18 ) & 1.83 (1.25 to 2.68$)$ \\
\hline & Alvelobuccal & 1.42 (0.98 to 2.06$)$ & 1.19 (0.80 to 1.75$)$ \\
\hline & Alveolus & 1.34 (0.86 to 2.07 ) & 1.13 (0.72 to 1.80$)$ \\
\hline & $C A \& F O M$ & 0.87 (0.52 to 1.43$)$ & 0.65 (0.38 to 1.11$)$ \\
\hline & RMT & 0.84 (0.46 to 1.55$)$ & 0.78 (0.41 to 1.46$)$ \\
\hline & Lip & 1.49 (0.83 to 2.67$)$ & 1.72 (0.94 to 3.13$)$ \\
\hline \multirow[t]{2}{*}{ Deg. of Diff. } & WD & 1 & 1 \\
\hline & Others & 1.34 (1.02 to 1.75$)$ & 1.41 (1.07 to 1.86$)$ \\
\hline Tumor Size & $<=2$ & 1 & 1 \\
\hline \multirow[t]{2}{*}{$(\mathrm{cm})$} & $>2$ and $<=4$ & 1.29 (0.95 to 1.75$)$ & 1.18 (0.86 to 1.63$)$ \\
\hline & $>4$ & 1.36 (0.95 to 1.96$)$ & 1.18 (0.80 to 1.74$)$ \\
\hline
\end{tabular}

UOR Unadjusted odds ratio, AOR Adjusted odds ratio.

*Adjusted in relation to smoking and clinical bone involvement when to relax the proportional odds assumption [48]. Under exploration of this possibility, either to use POM or PPOM, log likelihood, AIC and likelihood ratio test supported the PPOM. Also, a clinically relevant covariate, tumor size emerged to be significant under PPOM.

Table 3 Factors associated with cervical lymph node involvement using partial proportional odds model

\begin{tabular}{|c|c|c|c|}
\hline Variables & & UOR(95\%Cl) & $\mathrm{AOR}(95 \% \mathrm{Cl})^{*}$ \\
\hline \multirow[t]{2}{*}{ Pain } & No & 1 & 1 \\
\hline & Yes & 1.37 (1.07 to 1.77$)$ & $1.39(1.06$ to 1.81$)$ \\
\hline \multirow[t]{2}{*}{ SMF } & No & 1 & 1 \\
\hline & Yes & 0.44 (0.22 to 0.90$)$ & 0.43 (0.21 to 0.90$)$ \\
\hline \multirow[t]{2}{*}{ cNeck Node } & No & 1 & 1 \\
\hline & Yes & 2.28 (1.66 to 3.14$)$ & 2.44 (1.75 to 3.42 ) \\
\hline \multirow[t]{7}{*}{ Oral Site } & BM & 1 & 1 \\
\hline & Tongue & 1.53 (1.07 to 2.18$)$ & 1.83 (1.25 to 2.69$)$ \\
\hline & Alvelobuccal & 1.42 (0.98 to 2.06$)$ & 1.19 (0.80 to 1.76$)$ \\
\hline & Alveolus & 1.34 (0.86 to 2.07 ) & 1.15 (0.73 to 1.83$)$ \\
\hline & $C A \& F O M$ & 0.87 (0.52 to 1.43 ) & 0.65 (0.38 to 1.12$)$ \\
\hline & RMT & 0.84 (0.46 to 1.55$)$ & 0.77 (0.40 to 1.45$)$ \\
\hline & Lip & 1.49 (0.83 to 2.67$)$ & 1.72 (0.95 to 3.13 ) \\
\hline \multirow[t]{2}{*}{ Deg. of Diff. } & WD & 1 & 1 \\
\hline & Others & 1.34 (1.02 to 1.75$)$ & $1.42(1.07$ to 1.87$)$ \\
\hline Tumor Size & $<=2$ & 1 & 1 \\
\hline \multirow[t]{4}{*}{ (cm) } & $>2$ and $<=4$ & 1.30 (0.96 to 1.77$)$ & 1.19 (0.87 to 1.64$)$ \\
\hline & $>4$ & $1.20(0.83$ to 1.73$)$ & 1.01 (0.68 to 1.50$)$ \\
\hline & Cut2 & 1.69 (1.14 to 2.51$)$ & 1.47 (0.97 to 2.24) \\
\hline & Cut3 & 2.39 (1.35 to 4.22$)$ & 2.12 (1.18 to 3.79$)$ \\
\hline
\end{tabular}

UOR Unadjusted odds ratio, AOR Adjusted odds ratio. Cut2, category 4,3 vs. 2,1; Cut2, category 4 vs. 3, 2,1.; *Adjusted in relation to smoking and clinical bone involvement. 
Table 4 Comparison of the developed models

\begin{tabular}{llll}
\hline Model & LR & AIC & BIC \\
\hline POM & -988.79 & 2011.57 & 2094.04 \\
PPOM & -983.18 & 2004.37 & 2096.54 \\
\hline
\end{tabular}

The availability of GOLOGIT2 with AUTOFIT syntax in STATA makes the things easier to select the appropriate model between POM and PPOM [35, 42].

Results under binary form of nodal involvement on the same dataset and considering same set of covariates are already reported elsewhere [30, 31]. Under appropriate consideration of the nodal involvement in the ordinal form, one of the clinically more relevant covariates i.e., histopathological tumor size, was also found to be significantly associated with extent of nodal involvement, which was missed in its binary consideration. However, other significant covariates were similar and also the effect size was in same direction. Under model assessment, model for binary as well as ordinal form of nodal involvement described the distribution satisfactorily.

\section{Conclusions}

The analytical results under the present study reveal that in case of ordinal form of the outcome, ordinal regression may be a preferred choice. Further, in case of violation of proportionality assumption in any of the covariates, PPOM may be a better choice. This is likely to ensure accuracy not only in results but also in related inferences and their implications. In summary, pain at the time of presentation, sub mucous fibrosis, clinically palpable neck node, oral site, degree of differentiation and tumor size are the most probable associated factors with extent of nodal involvement in oral squamous cell carcinoma patients.

As mentioned earlier, the ordinal categories mainly relied on desired varying management strategies being adopted by the oncologists according to cut-off values of involved nodes. Otherwise, as true in case of any such study, change in cut-off values of nodal involvement is bound to change the results. Further, as true under such modeling, finite sample bias may remain a concern in these models as well.

\section{Abbreviations \\ POM: Proportional odds model; PPOM: Partial proportional odds model OSCC: Oral squamous cell carcinoma; RMT: Retromolar triangle; SMF: Sub mucous fibrosis; 95\%Cl: 95\% Confidence interval; LC: Lower class; LMC: Lower middle class; UC: Upper class; UMC: Upper middle class; \\ UIG: Ulceroinfiltrative; UPG: Ulceroproliferative; WD: Well Differentiated; Deg. of Diff: Degree of differentiation; cSkin Inv: Clinical skin involvement; cBone Inv: Clinical bone involvement; UOR: Unadjusted odds ratio; AOR: Adjusted odds ratio}

\section{Acknowledgements}

Thanks to All India Institute of Medical Sciences, New Delhi, for providing the required facilities. Also, thanks to the reviewers, and editor of the journal, for their valuable suggestions to improve the article further.

\section{Authors' contributions}

VS, SND and SVSD conceived and designed the study. VS did the analysis under supervision of SND. VS, SND and SVSD interpreted the results. The final draft of the manuscript was prepared by VS under supervision of SND and SVSD. Each of the three authors read and approved the final manuscript.

\section{Funding}

Nil. Present study is not funded by any external funding agency. It is part Ph.D. work of the first author.

\section{Availability of data and materials}

All the data are from the Department of Surgical Oncology, Dr. BRA-IRCH, All India Institute of Medical Sciences, New Delhi, India. The datasets are available upon request from SVS Deo.

\section{Ethics approval and consent to participate}

The present study was approved by Ethics Committee for Post graduate research, All India Institute of Medical Sciences, New Delhi, India. Consent to participate is not applicable.

\section{Consent for publication}

Not applicable.

\section{Competing interests}

The authors declare they have no competing interests.

\section{Author details}

'Department of Biostatistics, All India Institute of Medical Sciences, New Delhi 110029, India. ${ }^{2}$ Department of Surgical Oncology, Dr BRA-IRCH, All India Institute of Medical Sciences, New Delhi, India.

Received: 27 November 2019 Accepted: 20 April 2020

Published online: 26 April 2020

\section{References}

1. World Health Organization. International agency for research on cancer. GLOBOCAN 2012. <globocan.iarc.fr/pages/fact_sheets_cancer.aspx> [accessed 13-01-2015].

2. Karino M, Nakatani E, Hideshima K, et al. Applicability of preoperative nuclear morphometry to evaluating risk for cervical lymph node metastasis in oral squamous cell carcinoma. PLoS One. 2014;9:1-15.

3. De Matos LL, Manfro G, Dos Santos RV, et al. Tumor thickness as a predictive factor of lymph node metastasis and disease recurrence in T1NO and T2NO squamous cell carcinoma of the oral tongue. Oral Surg Oral Med Oral Pathol Oral Radiol. 2014;118:209-17.

4. Warburton G, Nikitakis NG, Roberson P, et al. Histopathological and Lymphangiogenic parameters in relation to lymph node metastasis in early stage Oral squamous cell carcinoma. J Oral Maxillofac Surg. 2007:475-84.

5. Mendez E, Fan W, Choi P, et al. Tumor-Specific Genetic Expression Profile Of Metastatic Oral Squamous Cell Carcinoma. Head Neck. 2007:803-14.

6. Massano J, Regateiro FS, Juanario G, et al. Oral squamous cell carcinoma: review of prognostic and predictive factors. Oral Surg Oral Med Oral Pathol Oral Radiol Endod. 2006;102(1):67-76.

7. Okura M, lida S, Aikawa T, Adachi T, et al. Tumor thickness and Paralingual distance of coronal MR imaging predicts cervical node. Am J Neuroradiol. 2008;29(1):45-50.

8. Deo SVS, Shukla NK, Jha D. Are we over-treating neck in Buccal \& Alveolobuccal Cancers: experience from a tertiary Cancer care center. Ind I Surg Oncol. 2012;3:272-5.

9. Hoch S, Fasunla J, Eivazi B, et al. Delayed lymph node metastases after elective neck dissection in patients with oral and oropharyngeal cancer and pN0 neck. Am J Otolaryngol Neck Med Surg. 2012;33:505-9.

10. Kim K-Y, Cha I-H. A novel algorithm for lymph node status prediction of oral cancer before surgery. Oral Oncol. 2011;47:1069-73.

11. Lim YC, Koo BS, Lee JS, et al. Level V lymph node dissection in Oral and Oropharyngeal carcinoma patients with clinically node-positive neck: is it absolutely necessary? Laryngoscope. 2006:1232-5.

12. Montes DM, Carlson ER, Fernandes $R$, et al. Oral maxillary squamous carcinoma: an indication for neck dissection in the clinically negative neck. Head Neck. 2011;33(11):1581-5. 
13. Liao C, Hsueh C, Lee $L$, et al. Neck dissection field and lymph node density predict prognosis in patients with oral cavity cancer and pathological node metastases treated with adjuvant therapy. Oral Oncol. 2012;48:329-36.

14. Wu K, Yang X, Li L, et al. Neurovascular invasion and histological grade serve as the risk factors of cervical lymph node metastases in early tongue squamous cell carcinoma. Mol Neurobiol. 2015;53(5):2920-6.

15. Kang C, Liao C, Hsueh C, et al. Outcome analysis of patients with welldifferentiated oral cavity squamous cell carcinoma. Oral Oncol. 2011:47: 1085-91.

16. Sekine J, Uehara M, Hideshima K, et al. Predictability of lymph node metastases by preoperative nuclear morphometry in squamous cell carcinoma of the tongue. Cancer Detect Prev. 2003;27:427-33.

17. Pimenta Amaral TM, Da Silva Freire AR, Carvalho AL, et al. Predictive factors of occult metastasis and prognosis of clinical stages I and II squamous cell carcinoma of the tongue and floor of the mouth. Oral Oncol. 2004;40:780-6.

18. Sekine J, Uehara M, Hideshima K, et al. Predictability of lymph node metastases by preoperative nuclear morphometry in squamous cell carcinoma of the tongue. Cancer Detect Prev. 2003;27(6):427-33.

19. Briggs RJS, Pienta KJ, Hruban H, et al. Nuclear Morphometry for prediction of metastatic potential in early squamous cell carcinoma of the floor of the mouth squamous. Archives of Otolaryngology. Head and Neck Surgery. 1992;118(5):531-3.

20. Chone CT, Aniteli MB, Magalhães RS, et al. Impact of immunohistochemistry in sentinel lymph node biopsy in head and neck cancer. Eur Arch Otorhinolaryngol. 2013:313-7.

21. Lim S, Zhang S, Ishii G, et al. Predictive markers for late cervical metastasis in stage I and II invasive squamous cell carcinoma of the Oral tongue. Clin Cancer Res. 2004;10:166-72.

22. Kawano K, Yanagisawa S. Original article predictive value of Laminin-5 and membrane type 1-matrix metalloproteinase expression for cervical lymph node metastasis in $\mathrm{T} 1$ and $\mathrm{T} 2$ squamous cell carcinomas of the tongue. Head Neck. 2006;28(6):525-33.

23. Harada H, Medical T, Omura K, et al. Cyclin B1 is useful to predict occult cervical lymph node metastases in tongue carcinoma Cyclin B1 is useful to predict occult cervical lymph node metastases in tongue carcinoma. J Exp Clin Cancer Res. 2006;25(3):351-6.

24. Byers RM, El-Naggar AK, Lee YY, et al. Can we detect or predict the presence of occult nodal metastases in patients with squamous carcinoma of the oral tongue? Head Neck. 1998;20:138-44.

25. d'Alessandro AF, Pinto FR, Lin CS, et al. Oral cavity squamous cell carcinoma: factors related to occult lymph node metastasis. Braz J Otorhinolaryngol. 2015;81:248-54.

26. Kowalski LP, Sanabria A. Elective neck dissection in oral carcinoma: a critical review of the evidence. Acta Otorhinolaryngol. 2007;27:113-7.

27. Suzuki M, Suzuki T, Asai M, et al. Clinicopathological factors related to cervical lymph node metastasis in a patient with carcinoma of the oral floor. Acta Otolaryngol. 2007;127:129-35.

28. Cande V Ananth, and David G Kleinbaum. Regression models for ordinal responces a review of methods and application. International journal of epidemiology. 1997; Vol. 26, No. 6.

29. Armstrong BB, Sloan M. Ordinal regression models for epidemiological data. Am J Epidemiol. 1989;129(1):191-204.

30. Singh V, Deo SVS, Dwivedi SN, et al. An Epidemiological Model to Find out Factors Associated with Nodal Involvement among. Ind Oral Cancer Patients Open J Epidemiol. 2018;8:117-29.

31. Singh V, Dwivedi AK, Dwivedi SN, et al. Comparative Appraisal of Estimated Odds Ratio and Risk Ratio Using Binary Regression Models: Analysis of Nodal Involvement Among Oral-Cancer Patients. Biostatistics Biometrics Open Access Journal. 2018;8(4)

32. Brant R. Assessing proportionality in the proportional odds model for ordinal logistic regression. Biometrics. 1990;46(4):1171-8.

33. Van Calster B, Van Belle V, Vergouwe $Y$, et al. Discrimination ability of prediction models for ordinal outcomes: relationships between existing measures and a new measure. Biom J. 2012;54(5):674-85.

34. Fagerlanda MW, Hosmer DW. A goodness-of-fit test for the proportional odds regression model Statistics in medicine. 2013;32(13):2235-49.

35. Scott Long J, Freese J. Regression models for categorical dependent variablesusing Stata. Third Edition. College Station: Stata Press; 2014.

36. Lipsitz SR, Fitzmaurice GM, Molenberghs G. Goodness-of-fit tests for ordinal response regression models. Appl Stat. 1996;45(2):175-90.
37. McCullagh P. Regression models for ordinal data (with discussion). J R Statis Soc Series B. 1980;42:109-42.

38. Cox C, Chuang C. A comparison of chi-square partitioning and two logit analyses of ordinal pain data from a pharmaceutical study. Stat Med. 1984;3: 273-85.

39. Ananth CV, Kleinbaum DG. Regression models for ordinal responses: a review of methods and applications. International Journal of Epidemiology. 1997; Vol. 26, No. 6.

40. Walker SH, Duncan DB. Estimation of the probability of an event as a function of several independent variables. Biometrika. 1967;54:167-79.

41. Peterson BL, Harrell FE. Partial proportional odds models for ordinal response variables. Appl Stat. 1990;39:205-17.

42. Richard Willianms. Generalized ordered logit/ partial proportional odds modes for ordinal dependent variables. The Stata Journal. 2006; Number 1, pp. 58-82.

43. Altman DG, Royston P. What do we mean by validating a prognostic model? Stat Med. 2000;19:453-73.

44. Sundaram KR, Dwivedi SN, Sreenivas V. Medical statistics principles \& methods. Wolter Kluwer. 2015; 2nd edition. Alphen Aan Den Rijn.

45. Vartanian JG, Carvalho AL, Filho d A, et al. Predictive factors and distribution of lymph node metastasis in lip Cancer patients and their implications on the treatment of the neck. Oral Oncol. 2004;40:223-7.

46. Angadi PV, Patil PV, Hallikeri K, et al. Tumor budding is an independent prognostic factor for prediction of lymph node metastasis in Oral squamous cell carcinoma. Int J Surg Pathol. 2015;23:102-10.

47. Samarakoon B, Samadarani M, Mudiynaselage R. Predictive model of Oral Cancer metastasis for different Cancer sites and age groups. J Investig Clin Dent. 2016;7:127-31.

48. Fullerton AS, Jun $X$. The proportional odds with partial proportionality constraints model for ordinal response variables. Soc Sci Res. 2012:182-98.

\section{Publisher's Note}

Springer Nature remains neutral with regard to jurisdictional claims in published maps and institutional affiliations.

Ready to submit your research? Choose BMC and benefit from:

- fast, convenient online submission

- thorough peer review by experienced researchers in your field

- rapid publication on acceptance

- support for research data, including large and complex data types

- gold Open Access which fosters wider collaboration and increased citations

- maximum visibility for your research: over $100 \mathrm{M}$ website views per year

At BMC, research is always in progress.

Learn more biomedcentral.com/submissions 